\title{
BMJ Open Prevalence and correlates of physical violence and rape among female sex workers in Ethiopia: a cross-sectional study with respondent-driven sampling from 11 major towns
}

\author{
Minilik Demissie Amogne, ${ }^{\oplus, 2}$ Taye Tolera Balcha, ${ }^{3}$ Anette Agardh ${ }^{1}$
}

To cite: Amogne MD, Balcha TT, Agardh A. Prevalence and correlates of physical violence and rape among female sex workers in Ethiopia: a cross-sectional study with respondent-driven sampling from 11 major towns. BMJ Open 2019;9:e028247. doi:10.1136/ bmjopen-2018-028247

- Prepublication history for this paper is available online. To view these files please visit the journal online (http://dx.doi org/10.1136/bmjopen-2018028247).

Received 28 November 2018 Revised 02 July 2019 Accepted 08 July 2019

Check for updates

(c) Author(s) (or their employer(s)) 2019. Re-use permitted under CC BY-NC. No commercial re-use. See rights and permissions. Published by BMJ.

${ }^{1}$ Social Medicine and Global Health, Lund University, Malmo, Sweden

${ }^{2} \mathrm{~TB} / \mathrm{HIV}$ Department, Ethiopian Public Health Institute, Addis Ababa, Ethiopia

${ }^{3}$ Director general, Armauer Hansen Research Institute, Addis Ababa, Ethiopia

Correspondence to Minilik Demissie Amogne; minilik.demissie@med.Iu.se

\section{ABSTRACT}

Objective This study examined the prevalence and correlates of physical violence and rape among female sex workers (FSWs) in Ethiopia.

Design A cross-sectional study using respondent-driven sampling technique.

Setting Eleven major towns in Ethiopia.

Participants 4900 FSWs.

Main outcome measures The prevalence of experiences of physical beating and rape.

Results Among FSWs, $17.5 \%$ reported physical beating within the last year and $15.2 \%$ reported rape since they started selling sex. FSWs aged $35+$ years (AOR 0.59, $95 \% \mathrm{Cl} 0.38$ to 0.92 ) were less exposed to physical beating than those aged 15-24 years. FSWs working on the street (AOR 1.92, 95\% Cl 1.53 to 2.39), in red-light houses (AOR 1.63, 95\% $\mathrm{Cl} 1.12$ to 2.38) and in local drinking houses (AOR 1.35, 95\% Cl 1.02 to 1.78) experienced more physical beating than FSWs working in bars/hotels. FSWs who consumed alcohol four or more days in a week (AOR 1.92, 95\% Cl 1.21 to 3.04), and who chewed khat frequently experienced more physical violence. Rape was associated with having a low monthly income, drinking alcohol four or more days per week (AOR $2.33,95 \% \mathrm{Cl}$ 1.47 to 3.7), experience of heavy episodic drinking in a month (AOR 1.71, 95\% Cl 1.24 to 2.38) and chewing khat 3-4 days per week (AOR 2.15, 95\% Cl 1.55 to 2.98). Condom breakage was more frequent among FSWs who reported both physical beating (AOR $1.51,95 \% \mathrm{Cl} 1.25$ to 1.84) and rape (AOR $1.26,95 \% \mathrm{Cl} 1.03$ to 1.55 ).

Conclusion FSWs in Ethiopia are vulnerable to physical and sexual violence, and the risk increases when they are younger, street-based and high consumers of alcohol or khat. Therefore, targeted efforts are needed for prevention and harm reduction.

\section{INTRODUCTION}

As per WHO definition, violence is the intentional use of physical force or power against another person or group, which has a high likelihood of resulting in injury, death, or sexual or psychological harm. ${ }^{1}$ Violence against women is a global phenomenon, as
Strengths and limitations of this study

- The study involves multiple sites (11 large towns) across the country with a large sample size.

- The study used a respondent-driven sampling, a technique that is recommended for hard to reach populations.

- Sexual and physical violence are sensitive topics that are subject to underreporting because of social desirability bias.

- Recall bias could have occurred because participants were asked about physical violence in the last year and rape since they started selling sex.

- Due to a cross-sectional study design, the influence of alcohol use/khat chewing must be interpreted with caution, since the participants' current consumption status might not be an accurate indicator of the consumption status at the time of the violence.

more than one in three women worldwide is beaten, coerced into sex or abused in her lifetime. ${ }^{2}$ Furthermore, violence is one of the main contributors to poor sexual and reproductive health among women, leading to unintended pregnancy, self-induced abortions, gynecological problems, sexual dysfunction and sexually transmitted infections (STIs), including HIV. ${ }^{34}$

In most countries, female sex work is either illegal or has an uncertain legal status. For example, prostitution is not illegal but approaching sex workers in public is illegal; this makes authorities reluctant to offer protection or support, which in turn legitimises violence and discrimination against sex workers. ${ }^{5}$ In the case of Ethiopia, it is illegal to operate a brothel or procure sex workers as a commercial activity, but the sale of sex by women is neither prohibited nor legally recognised as a profession. ${ }^{6}$ Female sex workers (FSWs) frequently 
face harassment and violence, not only because of their illegitimate status but also as a manifestation of gender inequality and discrimination directed towards women. ${ }^{78}$

Violence against FSWs can be perpetrated by anyone, including police officers, intimate partners and clients. In Adama and Mekelle towns in Ethiopia, $60 \%$ and $75 \%$ of FSWs, respectively, reported lifetime violence. ${ }^{9}{ }^{10}$ In the same study in Adama, $8 \%$ of FSW reported forced sex since they started sex work. ${ }^{10}$ In another study conducted among homeless street females in Bahirdar town, 11.4\% of them reported having been raped during the last 1 year period. ${ }^{11}$ In Uganda, $40 \%$ of FSWs reported physical abuse, and $49 \%$ had been raped at least once in their lifetime. ${ }^{12}$ In another study conducted in Hunan, China and Karnataka, India, $16 \%$ and $9 \%$ of FSWs, respectively, reported work-related violence. ${ }^{1314}$

Several risk factors have been found to have an association with physical and sexual violence against FSWs. Socioeconomic characteristics, risky sexual behaviours and substance abuse are the most mentioned factors worldwide. ${ }^{9} 101516$ A randomised controlled trial study in Kenya and South Africa showed that alcohol consumption reduction by FSWs had a significant contribution to violence reduction. ${ }^{17}{ }^{18}$ Moreover, establishments where alcohol and other drugs are consumed are associated with an increased likelihood of people becoming violent towards sex workers. ${ }^{8}{ }^{19}$ However, other studies suggest that FSWs who work outdoors face more violence than those who work indoors. ${ }^{20} 21$

Violence towards FSWs may also be associated with condom use and condom breakage. Studies conducted among FSWs have found several intentional and unintentional factors associated with condom breakage during sex work. These factors included being drunk or high on drugs, wearing unfitting condoms, incorrect condom use and having violent or rough sex. ${ }^{22}{ }^{23}$ Moreover, violence towards FSWs may also be linked to disagreement over condom use, which increases the risk of acquiring HIV and other STIs. ${ }^{21}{ }^{24-26}$ In Ethiopia, the weighted HIV prevalence among FSWs is estimated to be $23 \%,{ }^{27}$ while it is $1.2 \%$ in the general population, ${ }^{28}$ which shows the magnitude of the potential risk exposure among FSWs. In addition, violence also prevents sex workers from seeking appropriate health services. ${ }^{26} 2930$

In general, 120000-160000 FSWs are estimated to live in Ethiopia, working in different venues, mainly in bars and hotels, Key-mebrat (red lighthouses), local drinking houses and on the street. ${ }^{27}$ Currently, the number of FSWs is growing, with increasing numbers of young girls entering the sex trade.

This study explores the prevalence and correlates of physical violence and rape among FSWs in Ethiopia. Successful strategies for handling the trauma may vary by the type of violence experienced. Therefore, identification of risk factors that are specific to various types of violence has the potential to inform the development of evidence-based prevention programme. In addition, generating such types of evidence based on national level data will help to promote effective prevention for FSWs.

\section{METHODS}

\section{Study design}

This study was part of a larger study concerning HIV prevalence and related risk factors among FSWs and long-distance drivers that was carried out in Ethiopia in 2014. A cross-sectional study design using respondent-driven sampling (RDS) technique was used for data collection. RDS is a complex sampling method based on a chain-referral design and recommended for hard-to-reach populations. At all data collection sites, initial FSW 'seeds' were selected to start the sampling process. Seeds were selected purposively to represent the type of sex worker, age category and geographic location. They were identified through formative assessments with key stakeholders working with FSWs and representatives of FSWs. The selected seeds were those who were well-connected with their community and reported large social networks.

A maximum of three recruits per seed was allowed and only one-time participation was ensured by using a fingerprint-scanning device. Recruitment pattern (who recruited whom) was tracked and network size was determined.

\section{Study area, period and population}

The study locations were the seven major regional towns and the four main transport corridor towns. The seven major regional towns were: Addis Ababa, Bahir Dar, Mekelle, Hawassa, Adama, Gambela and Dire Dawa. The four transport corridor towns were Semera-Logia (Addis Ababa-Djibouti route), Kombolcha (Addis Ababa-Mekelle route), Metema (Addis Ababa-Metema route) and Shashemene (Addis Ababa-Moyale route).

The source populations were all FSWs living in those selected 11 towns. For the purpose of the study, FSWs were defined as follows: "women who practice sexual activity with the pre-conditions of financial or in-kind benefits'. The inclusion criteria were receiving money or other benefits for sex with four or more people within the last 30 days, being 15 and above years old, properly recruited by a peer (presenting with the coupon), and giving consent both for the interview and blood drawing.

\section{Sample size}

The source study protocol calculated that a sample size of 400 FSWs was needed in each town using anticipated HIV prevalence of 25\%, $6 \%$ precision, $95 \%$ CI and design effect of two. However, the number of FSWs who participated in each town was not exactly 400 , and the total number of FSWs who participated in the study was 4900 .

\section{Data collection procedure}

Six seed FSWs were selected to initiate coupon-based recruitment. Eligible FSWs who provided informed consent to participate were administered a face-to-face 
interview in a private room by a nurse with a structured questionnaire in Amharic language. They then provided blood specimens for HIV, CD4 and viral load testing in a private room. When the process was completed, participants were provided with up to three coupons and instructed to recruit their FSW peers into the study. To compensate the time and costs of transport, a primary incentive of 100 ETB (US\$5.0) and additional 50 ETB (\$2.5) for each eligible peer she enrolled into the study was given. An electronic data base for tracking coupons and recruitment was established with participant ID, fingerprint code and a preprinted label that was scanned. The data collection tools and questionnaire were pretested in a pilot study; feedback from the pilot study was used to finalise the data collection tools and field logistic and operational procedures. The questionnaire included: sociodemographic characteristics, sexual risk exposure, sexual behaviours, condom use, history of STI symptoms, alcohol and drug use consumption, violence-related issues, knowledge of HIV transmission and HIV-testing history.

\section{Variables}

Violence was assessed with two dependent variables, which were physical beating during the last 1 year and rape since sex selling started. The following questions were asked: 'When exchanging sex for money during the last 1 year, have you ever been physically beaten by a sexual partner or client?' and 'Have you ever been raped or forced to have sex against your will since you start selling sex?'. Responses were dichotomised into a yes and no variable for analysis. For both of the questions, all who had reported beating and rape at least once were considered as having experienced violence (yes).

The different time periods used to assess experiences of physical beating and rape were based on the presumed frequency of the two different types of violence. Physical beating might occur more frequently, while rape presumably occurs less frequently. Therefore, to measure the general burden of the two experiences, we specifically selected the time period that might be appropriate for the recall of the particular experience.

The independent measures included current age, monthly income from selling sex, marital status, educational status, sex-selling venue, khat chewing, alcohol drinking, HIV status and condom breakage.

Current age was a continuous variable and for the purpose of analysis categorised as 10-year intervals: younger ${ }^{15-24}$ middle age,${ }^{25-34}$ and older one (35+), with the younger age group used as the reference category. Monthly income from selling sex was an open-ended question and for the analysis was categorised into 1000 birr ( $\$ 50)$ intervals considering the cost of living in the country. Educational status was categorised as no formal education, primary first cycle (grades 1-4), primary second cycle (grades 5-8) and secondary and above for analysis, in accordance with the country education system.
In addition, sex workers were categorised based on their sex-selling venue, where bar/hotel was used as the reference because it is the most common FSW working venue. In addition, this venue category has better security than the other venues, and there were greater numbers of FSWs in this category.

Alcohol consumption was measured by different indicators, including frequency of alcohol consumption, number of drinks per specific day and frequency of heavy episodic drinking (HED) (six or more standard drinks per day).

Frequency of khat chewing was assessed according to the number of days that they chewed in a week. Khat (Catha edulis) is a stimulant leaf, and after chewing khat, an individual may become talkative, alert, feel excitement, increased self-esteem and increased imagination. ${ }^{31}$ Khat chewing is also popular among FSWs, as it is a means to spend the daytime, to be active during the night for sex work and to socialise with each other.

\section{Data analysis}

Statistical analysis was performed using SPSS V.20. Descriptive statistics were used to provide summary measures (means, frequencies). ORs (crude and adjusted) and 95\% CI were obtained using bivariate and multivariate logistic regression analysis. Those independent variables significantly associated with the outcome variable in the bivariate analysis were included in the multivariate analysis. In addition, correlation analysis was performed to examine potential multicollinearity; no correlation was found between the variables. Cases with missing data were excluded from the analyses. Significance was accepted at $\mathrm{p}$ value $<0.05$.

During data collection, we did not specifically assess where FSWs experienced the violence (in the current town or in another town). Because FSWs are highly mobile from one town to another, it would be inaccurate to assume that their experiences of violence occurred in the town from which they were sampled. Therefore, during analysis, we did not conduct any statistical analysis that assessed the contribution of the sampling site (participant's town) to the experience of violence.

\section{Ethical considerations}

Permission for data use was obtained from the Ethiopian Public Health Institute (EPHI). The protocol was cleared at the Scientific and Ethical Research Office of EPHI, the Ethiopian Science and Technology Ministry Ethical Committee and CDC-Atlanta IRB. Individual written informed consent was obtained from each participant for the interview and blood sample collection while the study was conducted.

\section{Patient and public involvement}

During the design or implementation of the study, no patients were involved in the development of the research question and outcome measures. Nevertheless, due to the nature of the RDS methodology, an assessment was 
conducted to identify seeds and hotspot areas for the actual data collection. This assessment was conducted in collaboration with organisations working with FSWs and an active member of FSWs in those organisations. The primary results will be disseminate by publication in peer-reviewed journals and presented at the national level for stakeholders working with FSWs.

\section{RESULTS}

\section{Sociodemographic and other background characteristics}

A total of 4900 FSWs participated in the study. Demographic, socioeconomic and other background characteristics of the participants are shown in table 1 . The majority of the participants were between 15 and 24 years old with a mean age of 24 years $(\mathrm{SD}=5.7) ; 44 \%$ of them were divorced, separated or widowed. A quarter of them reported being uneducated and $40 \%$ of them earned on average less than $\$ 50$ per month. Regarding sex selling starting age, the majority started selling sex between the ages of 18 and 24 years, although $~ 25 \%$ started before the age of 18. FSWs work in different eating, drinking and recreation establishments, as well as other venues; $33 \%$ recruited their clients in bars/hotels, followed by $26.5 \%$ on the street, and $20 \%$ in local drinking houses (table 1).

\section{Behavioral and other related factors}

Table 2 shows the prevalence of behavioural and other factors. The majority $(70 \%)$ of the respondents consumed alcohol, and of those, $15.8 \%$ had drunk so much on a typical day within the last 30 days that they did not remember what happened the next day. About half of the respondents chewed khat, and $23.8 \%$ of them chewed almost every day (5-7 days a week).

Regarding condom use, $25.5 \%$ of them reported condom breakage within the last 30 days prior to the study. HIV/AIDS status of the respondents was also assessed and a quarter of them (23\%) were HIV positive. With regard to physical and sexual violence experience, $17.5 \%$ of them reported physical beating within the last 12 months and $15.2 \%$ reported having been raped since they started selling sex (table 2).

\section{Bivariate regression analysis outcome}

Table 3 shows the bivariate logistic regression results; each independent variable was analysed separately against the two outcome variables. The variables that were significantly associated with physical violence were age, educational level, average monthly income from selling sex, current marital status, sex-selling venues, frequency of alcohol consumption, alcohol containing drinks on a typical day, frequency of HED, frequency of khat chewing in a week and condom breakage. Variables significantly associated with rape were educational level, average monthly income from selling sex, frequency of alcohol consumption, alcohol containing drinks on a typical day, frequency of HED, frequency of khat chewing in a week
Table 1 Distribution of sociodemographic and other background characteristics among 4900 female sex workers across 11 towns, Ethiopia

\begin{tabular}{|c|c|c|}
\hline Variable & Frequency & Percentage \\
\hline \multicolumn{3}{|l|}{ Age (years) } \\
\hline $15-24$ & 2831 & 57.8 \\
\hline $25-34$ & 1700 & 34.7 \\
\hline $35+$ & 369 & 7.5 \\
\hline Total & 4900 & 100.0 \\
\hline Missing & 0 & \\
\hline \multicolumn{3}{|l|}{$\begin{array}{l}\text { Mean age of respondents=24.16 } \\
\mathrm{SD}=5.7\end{array}$} \\
\hline \multicolumn{3}{|l|}{ Educational status } \\
\hline No education & 1224 & 25.0 \\
\hline Primary first cycle (1-4) & 764 & 16.0 \\
\hline Primary second cycle (5-8) & 2062 & 42.0 \\
\hline Secondary and above & 831 & 17.0 \\
\hline Total & 4881 & 100.0 \\
\hline Missing & 19 & \\
\hline \multicolumn{3}{|l|}{ Sex-selling venues } \\
\hline Bar/hotel & 1613 & 33.0 \\
\hline Local drinking houses & 983 & 20.1 \\
\hline $\begin{array}{l}\text { Spa/massage/beauty salon/own } \\
\text { house }\end{array}$ & 261 & 5.3 \\
\hline Red-light houses & 429 & 8.8 \\
\hline Street & 1295 & 26.5 \\
\hline Other & 304 & 6.2 \\
\hline Total & 4885 & 100.0 \\
\hline Missing & 15 & \\
\hline \multicolumn{3}{|l|}{ Current marital status } \\
\hline Never married & 2698 & 55.2 \\
\hline Married/cohabited & 37 & 0.8 \\
\hline Separated/divorced & 1976 & 40.5 \\
\hline Widowed & 173 & 3.5 \\
\hline Total & 4884 & 100.0 \\
\hline Missing & 16 & \\
\hline \multicolumn{3}{|l|}{ Sex selling starting age } \\
\hline Less than 15 & 120 & 2.5 \\
\hline $15-17$ & 1088 & 22.3 \\
\hline $18-24$ & 2864 & 58.7 \\
\hline $25-29$ & 583 & 12.0 \\
\hline 30 and above & 220 & 4.5 \\
\hline Total & 4875 & 100.0 \\
\hline Missing & 25 & \\
\hline \multicolumn{3}{|l|}{ Monthly income from selling sex } \\
\hline Less than $1000(<\$ 50)$ & 1932 & 39.6 \\
\hline $1001-2000(\$ 50-\$ 100)$ & 1554 & 31.8 \\
\hline $2001-3000(\$ 100-\$ 150)$ & 812 & 16.6 \\
\hline $3001-4000(\$ 150-\$ 200)$ & 318 & 6.5 \\
\hline $4001-5000(\$ 200-\$ 250)$ & 150 & 3.1 \\
\hline Above $5000(>\$ 250)$ & 117 & 2.4 \\
\hline Total & 4883 & 100.0 \\
\hline Missing & 17 & \\
\hline
\end{tabular}


Table 2 Behavioural and other related factors among 4900 female sex workers across 11 towns, Ethiopia

\begin{tabular}{lcc}
\hline Variable & Frequency & Percentage \\
\hline Frequency alcohol consumption & & \\
Never & 1493 & 30.6 \\
Once a month or less & 222 & 4.5 \\
2-4 days a month & 492 & 10.1 \\
2-3 days a week & 1394 & 28.5 \\
4 or more days a week & 1283 & 26.3 \\
Total & 4884 & 100.0 \\
Missing & 16 & \\
\hline
\end{tabular}

Alcohol containing drinks on a typical day

\begin{tabular}{|rrr}
\hline or 2 & 806 & 23.8 \\
\hline 3 or 4 & 1383 & 40.8 \\
\hline 5 or 6 & 742 & 21.9 \\
7 to 9 & 296 & 8.7 \\
\hline 10 or more & 164 & 4.8 \\
\hline Total & 3391 & 100.0 \\
\hline Missing & 0 & \\
\hline Frequency of heavy episodic drinking & \\
\hline Never & 1863 & 54.9 \\
\hline Less than monthly & 236 & 7.0 \\
\hline Monthly & 299 & 8.8 \\
\hline Weekly & 630 & 18.6 \\
\hline Daily or almost daily & 363 & 10.7 \\
\hline Total & 3391 & 100.0 \\
\hline
\end{tabular}

Missing

0

Drunk so much and cannot remember what happened the next day

\begin{tabular}{|c|c|c|}
\hline Yes, in last 30 days & 534 & 15.8 \\
\hline Yes, not in last 30 days & 233 & 6.9 \\
\hline No & 2609 & 77.2 \\
\hline Do not remember & 4 & 0.1 \\
\hline Total & 3380 & 100.0 \\
\hline Missing & 11 & \\
\hline \multicolumn{3}{|l|}{ Frequency of khat chewing } \\
\hline Never & 2431 & 49.8 \\
\hline Less than once a week & 577 & 11.8 \\
\hline $1-2$ days per week & 429 & 8.8 \\
\hline 3-4 days per week & 284 & 5.8 \\
\hline 5-7 days per week & 1162 & 23.8 \\
\hline Total & 4883 & 100.0 \\
\hline Missing & 17 & \\
\hline \multicolumn{3}{|c|}{ Condom breakage in the last 30 days } \\
\hline Yes & 1243 & 25.5 \\
\hline No & 3635 & 74.5 \\
\hline Total & 4878 & \\
\hline Missing & 22 & \\
\hline \multicolumn{3}{|l|}{ HIV status } \\
\hline Negative & 3708 & 76.0 \\
\hline Positive & 1173 & 24.0 \\
\hline Total & 4881 & 100.0 \\
\hline Missing & 19 & \\
\hline
\end{tabular}

Continued
Table 2 Continued

\begin{tabular}{lcc}
\hline Variable & Frequency & Percentage \\
\hline \multicolumn{2}{l}{ Ever been raped or forced to have sex since start selling sex } \\
No & 4142 & 84.8 \\
Yes & 742 & 15.2 \\
Total & 4884 & 100.0 \\
Missing & 16 & \\
Physically beaten in the last $\mathbf{1 2}$ months & \\
No & 4026 & 82.5 \\
Yes & 855 & 17.5 \\
Total & 4881 & 100.0 \\
Missing & 19 & \\
\hline
\end{tabular}

and condom breakage. HIV status was not significantly associated with either physical violence or rape.

\section{Multivariate analysis of factors associated with physical violence (physically beaten)}

Table 4 shows the results of the multivariate analysis used to identify factors associated with physical violence after simultaneously adjusting for all measures included in the analyses. FSWs aged 35 years or above (AOR $0.59,95 \%$ CI 0.38 to 0.92 ) were significantly less likely to experience physical violence when compared with the younger age group (15-24 years). FSWs who had attended primary first cycle education (AOR 0.71, 95\% CI 0.52 to 0.97 ) were also less likely to experience physical beating than those who reported no education. On the other hand, FSWs who worked on the street (AOR 1.92, 95\% CI 1.53 to 2.39), in red-light houses (AOR 1.63, 95\% CI 1.12 to 2.38) and in local drinking houses (AOR 1.35, 95\% CI 1.02 to 1.78 ) had an increased odds of experiencing physical violence compared with FSWs who worked in bars/ hotels. Moreover, substance use was significantly related to physical violence. FSWs who consumed alcohol four or more days in a week (AOR 1.92, 95\% CI 1.21 to 3.04), those who did not remember what happened the next day due to heavy alcohol consumption both in the last 30 days (AOR 1.98, 95\% CI 1.58 to 2.49) and before the last 30 days (AOR 1.85, 95\% CI 1.35 to 2.53), and FSWs who chewed khat 3-4 days per week (AOR 1.58, 95\% CI 1.13 to 2.21 ) and 5-7 days per week (AOR $1.43,95 \%$ CI 1.13 to 1.80) had more likelihood of experiencing physical violence. Condom breakage experience within the last 30 days prior to the study was also significantly associated with physical violence (AOR 1.51, 95\% CI 1.25 to 1.84).

\section{Multivariate analysis of factors associated with sexual violence (rape)}

Table 5 shows the results of the multivariate logistic regression analyses used to identify factors that were significantly associated with rape after simultaneously adjusting for all measures included in the analyses. FSWs with a monthly income of $\$ 50$ to $\$ 200$ were significantly less likely to experience rape compared with those with a monthly income of below $\$ 50$. Drinking alcohol four 
Table 3 Bivariate logistic regression analyses of independent variables associated with physically beaten in the last 12 months and ever been raped since start selling sex, OR and $95 \% \mathrm{Cl}$

\begin{tabular}{|c|c|c|}
\hline Variables & $\begin{array}{l}\text { Physical beating } \\
\text { OR }(95 \% \mathrm{Cl})\end{array}$ & $\begin{array}{l}\text { Rape } \\
\text { OR }(95 \% \mathrm{Cl})\end{array}$ \\
\hline \multicolumn{3}{|l|}{ Age (years) } \\
\hline \multicolumn{3}{|l|}{$15-24^{*}$} \\
\hline $25-34$ & $1.02(0.87$ to 1.19$)$ & $1.02(0.86$ to 1.21$)$ \\
\hline $35+$ & $0.52(0.37$ to 0.74$)$ & 0.88 (0.64 to 1.20$)$ \\
\hline \multicolumn{3}{|l|}{ Educational level } \\
\hline \multicolumn{3}{|l|}{ No education* } \\
\hline Primary first cycle (1-4) & $1.01(0.79$ to 1.31$)$ & 1.45 (1.14 to 1.85$)$ \\
\hline Primary second cycle (5-8) & 1.35 (1.11 to 1.63$)$ & 1.08 (0.88 to 1.32$)$ \\
\hline Secondary and above & 1.49 (1.18 to 1.87$)$ & 1.09 (0.85 to 1.41$)$ \\
\hline \multicolumn{3}{|l|}{ Monthly income from selling sex } \\
\hline \multicolumn{3}{|l|}{ Less than 1000 birr $(<\$ 50)^{*}$} \\
\hline 1001-2000 birr $(\$ 50-\$ 100)$ & 1.44 (1.20 to 1.73$)$ & $0.69(0.58$ to 0.85$)$ \\
\hline 2001-3000 birr $(\$ 100-\$ 150)$ & 1.67 (1.35 to 2.07$)$ & 0.51 (0.39 to 0.66$)$ \\
\hline 3001-4000 birr $(\$ 150-\$ 200)$ & 1.61 (1.19 to 2.17$)$ & 0.65 (0.46 to 0.92$)$ \\
\hline 4001-5000 birr (\$200-\$250) & 2.12 (1.44 to 3.14$)$ & 1.01 (0.66 to 1.55$)$ \\
\hline Above 5000 birr $(>\$ 250)$ & 1.62 (1.01 to 2.58$)$ & 0.75 (0.44 to 1.27$)$ \\
\hline \multicolumn{3}{|l|}{ Current marital status } \\
\hline \multicolumn{3}{|l|}{ Never married } \\
\hline Married/cohabited & 1.05 (0.46 to 2.41$)$ & 0.69 (0.24 to 1.96$)$ \\
\hline Separated/divorced & 0.93 (0.80 to 1.09$)$ & $1.03(0.88$ to 1.21$)$ \\
\hline Widowed & 0.59 (0.37 to 0.95$)$ & 1.39 (0.95 to 2.06$)$ \\
\hline \multicolumn{3}{|l|}{ Sex-selling venues } \\
\hline \multicolumn{3}{|l|}{ Bar/hotel ${ }^{\star}$} \\
\hline Local drinking houses & 0.87 (0.69 to 1.09$)$ & - \\
\hline Spa/massage/beauty salon/own house & $0.45(0.28$ to 0.71$)$ & - \\
\hline Red-light houses & 0.95 (0.71 to 1.27$)$ & - \\
\hline Street & 1.51 (1.26 to 1.82$)$ & - \\
\hline Other & $1.37(1.01$ to 1.86$)$ & - \\
\hline \multicolumn{3}{|l|}{ Frequency alcohol consumption } \\
\hline \multicolumn{3}{|l|}{ Never* } \\
\hline $2-4$ days a month & 1.82 (1.35 to 2.44$)$ & 1.74 (1.27 to 2.38$)$ \\
\hline 2-3 days a week & 2.07 (1.66 to 2.57 ) & 1.87 (1.48 to 2.36$)$ \\
\hline 4 or more days a week & 3.54 (2.87 to 4.37$)$ & $3.43(2.75$ to 4.28$)$ \\
\hline \multicolumn{3}{|l|}{ Alcohol containing drinks on a typical day } \\
\hline \multicolumn{3}{|l|}{1 or $2^{*}$} \\
\hline 3 or 4 & 1.39 (1.09 to 1.76$)$ & 1.16 (0.92 to 1.46$)$ \\
\hline 5 or 6 & 2.03 (1.58 to 2.62$)$ & 1.09 (0.84 to 1.43$)$ \\
\hline 7 to 9 & 2.19 (1.59 to 3.03$)$ & 0.98 (0.68 to 1.41$)$ \\
\hline 10 or more & 2.76 (1.88 to 4.03$)$ & 1.78 (1.20 to 2.65$)$ \\
\hline \multicolumn{3}{|l|}{ Frequency of heavy episodic drinking } \\
\hline \multicolumn{3}{|l|}{ Never* } \\
\hline Less than monthly & $1.43(1.03$ to 1.98$)$ & 1.39 (0.99 to 1.95$)$ \\
\hline Monthly & $1.23(0.90$ to 1.66$)$ & 1.59 (1.18 to 2.13$)$ \\
\hline
\end{tabular}


Table 3 Continued

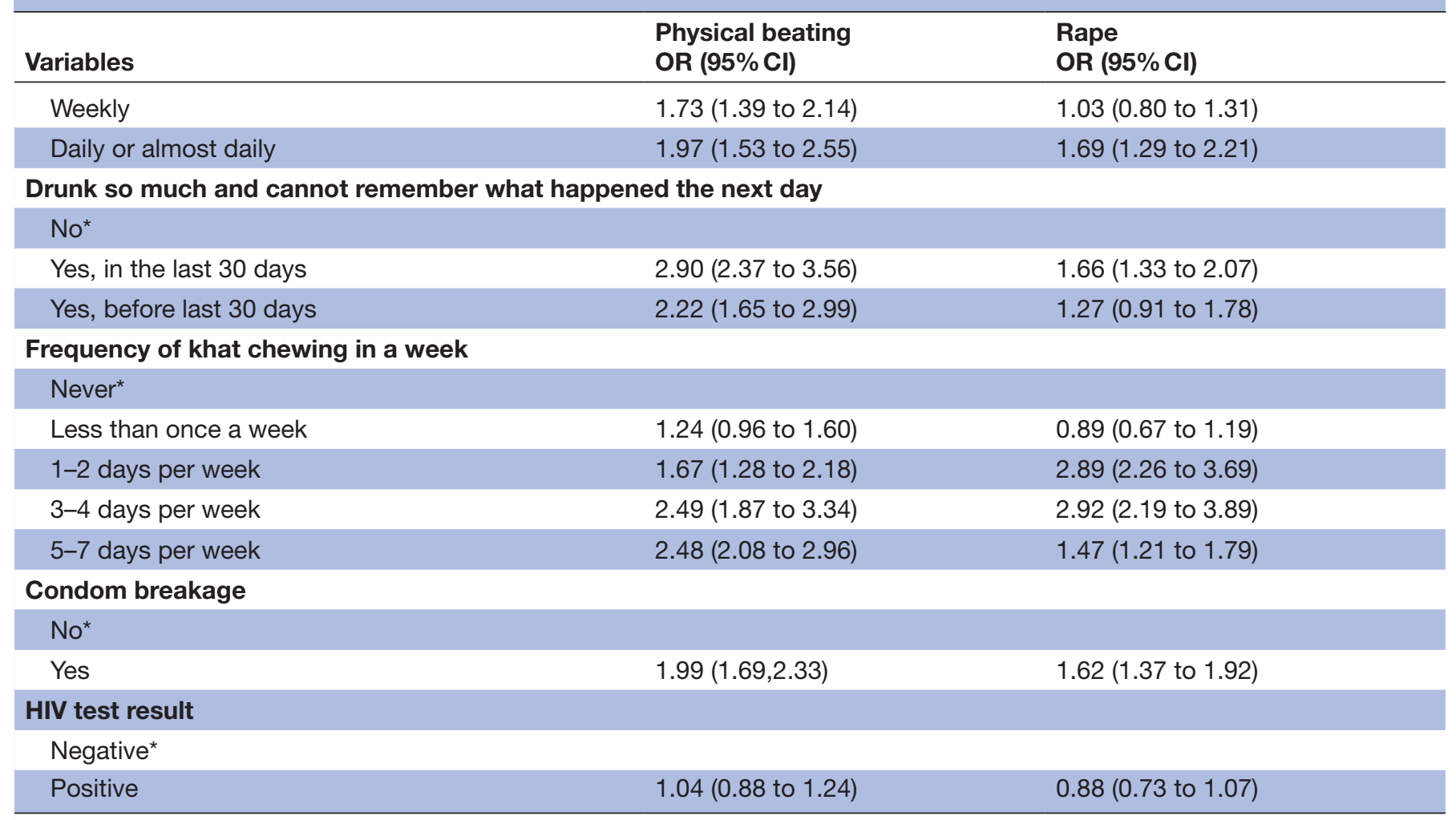

${ }^{\star}$ Reference category.

or more days per week (AOR 2.33, 95\% CI 1.47 to 3.7 ), experience of heavy drinking in the last 30 days and not remembering what happened the next day (AOR 1.34, $95 \%$ CI 1.05 to 1.72 ), experience of HED in a month (AOR 1.71, 95\% CI 1.24 to 2.38), experience of HED almost daily (AOR $1.49,95 \%$ CI 1.06 to 2.11 ) and chewing khat 1-2 days (AOR 2.13, 95\% CI 1.61 to 2.83) and 3-4 days (AOR 2.15, 95\% CI 1.55 to 2.98) per week were positively associated with rape. Moreover, condom breakage (AOR $1.26,95 \%$ CI 1.03 to 1.55 ) was significantly more frequent among FSWs who reported rape.

\section{DISCUSSION}

According to this study, $17.5 \%$ of FSWs in Ethiopia had been physically beaten within the last 12 months and $15.2 \%$ had been raped since they started selling sex. Age, sex-selling venues and high consumption of alcohol and khat were significant predictors of physical violence (beating). On the other hand, the significant predictors of sexual violence (rape) were low income and high consumption of alcohol and khat.

The prevalence of both physical violence and sexual violence (rape) was lower than the prevalence found in studies conducted in Uganda, Ivory Coast and Kenya. ${ }^{9} 123032$ However, when compared with the studies conducted in Adama (Ethiopia), China, India and Mexico, the current study reported a higher prevalence of both physical and sexual violence. ${ }^{1011} 131433$ The difference in the definition of violence used might be one of the possible explanations for the difference between the current result and those found in other studies in Africa. Most of the studies assessed all forms of physical and sexual violence while the current study assessed solely physical beating and forced penetrative sex (rape). On the other hand, differences in results across settings might also be due to differences in background and contextual factors such as socioeconomic status and cultural aspects.

Several studies showed that younger FSWs are more exposed to physical and sexual violence ${ }^{13} 34$ in line with the current findings that younger FSWs (15-24 years) were at higher risk for physical violence when compared with their older counterparts (35+ years). Perpetrators find it easier to manipulate younger FSWs and this might play a role in their increased exposure to violence. That younger FSWs are especially vulnerable to violence has important implications due to the increasing number of younger FSWs who are entering the sex trade. Therefore, to minimise the vulnerability of younger FSWs, intervention programme need to create awareness about the factors that increase the likelihood of violence and to ensure that younger FSWs are particularly addressed in such programme.

Even though sex work is not a legally recognised profession in Ethiopia, most of the establishments where the sex 
Table 4 Multivariate logistic regression analysis of factors associated with physical violence (physically beaten) in the last 12 months among female sex workers across 11 towns in Ethiopia, OR and $95 \% \mathrm{Cl}$

\begin{tabular}{ll}
\hline Variables & OR $(95 \% \mathrm{Cl})$ \\
\hline Age (years) &
\end{tabular}

$15-24^{*}$

$\begin{array}{ll}25-34 & 1.04(0.82 \text { to } 1.22) \\ 35+ & 0.59(0.38 \text { to } 0.92)\end{array}$

\section{Educational level}

No education*

$\begin{array}{ll}\text { Primary first cycle (1-4) } & 0.71(0.52 \text { to } 0.97) \\ \text { Primary second cycle (5-8) } & 0.98(0.77 \text { to } 1.26) \\ \text { Secondary and above } & 1.14(0.85 \text { to } 1.53)\end{array}$

Monthly income from selling sex

Less than 1000 birr $(<\$ 50)$ *

1001-2000 birr $(\$ 50-\$ 100)$

$1.13(0.90$ to 1.41$)$

2001-3000 birr (\$100-\$150)

1.14 (0.87 to 1.48$)$

3001-4000 birr (\$150-\$200)

$1.12(0.77$ to 1.61$)$

4001-5000 birr (\$200-\$250)

1.44 (0.93 to 2.24$)$

Above 5000 birr (>\$250)

1.12 (0.63 to 1.99$)$

\section{Current marital status}

Never married*

$\begin{array}{ll}\text { Married/cohabited } & 0.68(0.24 \text { to } 1.89) \\ \text { Separated/divorced } & 1.08(0.88 \text { to } 1.29) \\ \text { Widowed } & 0.87(0.48 \text { to } 1.59)\end{array}$

Sex-selling venues

Bar/hotel $^{*}$

\begin{tabular}{ll} 
Local drinking houses & $1.35(1.02$ to 1.78$)$ \\
$\begin{array}{l}\text { Spa/massage/beauty salon/own } \\
\text { house }\end{array}$ & $1.04(0.58$ to 1.84$)$ \\
$\begin{array}{l}\text { Red-light houses } \\
\text { Street }\end{array}$ & $1.63(1.12$ to 2.38$)$ \\
Other & $1.92(1.53$ to 2.39$)$ \\
\hline
\end{tabular}

Frequency alcohol consumption

Never*

\begin{tabular}{ll}
\hline 2-4 days a month & $1.25(0.77$ to 2.04$)$ \\
\hline $2-3$ days a week & $1.32(0.84$ to 2.06$)$ \\
4 or more days a week & $1.92(1.21$ to 3.04$)$ \\
\hline
\end{tabular}

\section{Alcohol containing drinks on a} typical day

\begin{tabular}{ll}
\hline or $2^{*}$ & \\
\hline 3 or 4 & $1.08(0.84$ to 1.39$)$ \\
5 or 6 & $1.15(0.85$ to 1.57$)$ \\
7 to 9 & $1.09(0.74$ to 1.64$)$ \\
10 or more & $1.14(0.72$ to 1.81$)$ \\
\hline $\begin{array}{l}\text { Frequency of heavy episodic } \\
\text { drinking }\end{array}$ & \\
\hline
\end{tabular}

Continued
Table 4 Continued

\begin{tabular}{ll}
\hline Variables & OR $(95 \% \mathbf{C l})$ \\
\hline Never $^{\star}$ & \\
\hline Less than monthly & $1.07(0.75$ to 1.52$)$ \\
\hline Monthly & $0.84(0.59$ to 1.18$)$ \\
Weekly & $1.07(0.82$ to 1.39$)$ \\
\hline Daily or almost daily & $0.99(0.71$ to 1.38$)$ \\
\hline
\end{tabular}

Drunk so much and cannot

remember what happened the next

day

\begin{tabular}{ll} 
No* & \\
Yes, in the last 30 days & $1.98(1.58$ to 2.49$)$ \\
Yes, before last 30 days & $1.85(1.35$ to 2.53$)$ \\
Frequency of khat chewing in a \\
week \\
Never* \\
Less than once a week \\
$\begin{array}{l}\text { 1-2 days per week } \\
\text { 3-4 days per week }\end{array}$ \\
$\begin{array}{l}\text { 5-7 days per week } \\
\text { Condom breakage }\end{array}$ \\
$\begin{array}{l}\text { No* } \\
\text { Yes }\end{array}$ \\
\hline
\end{tabular}

${ }^{*}$ Reference category.

workers are based (hotels, bars/restaurants, nightclubs and so on) operate legally with working licenses. Nevertheless, some FSWs work on the street and in red-light houses where they manage their own working area. Consequently, the extent to which physical violence occurs may vary according to their working area. The present study revealed that FSWs who mainly work in bars and hotels face less physical beating when compared with FSWs who work on the street, in red-light houses and local drinking houses. This finding is in line with studies conducted in New York City and England. ${ }^{20}{ }^{21}$ This might be due to the level of protection in their working areas and/or due to the type of clients who frequents those localities. This means that engaging bar/hotel managers in the prevention activities could be an additional strategy to decrease violence against FSWs.

On the other hand, FSWs who work on the street, in red-light houses and local drinking houses experienced more violence. Most of these venues are located in the slum areas of the cities, and such areas are often the focus of police efforts to control various unwanted activities. In this regard, FSWs are targets of harassment, physical violence and arrest by police. The actions of the police towards FSWs might also serve to legitimise violence against FSWs in the community (especially among FSWs residing in slum areas), thus increasing such acts of violence. Therefore, to minimise the harm in these 
Table 5 Multivariate logistic regression analysis of factors associated with sexual violence (rape) since sex selling start among female sex workers across 11 towns in Ethiopia, OR and $95 \% \mathrm{Cl}$

\begin{tabular}{|c|c|}
\hline Variables & OR $(95 \% \mathrm{Cl})$ \\
\hline \multicolumn{2}{|l|}{ Monthly income from selling sex } \\
\hline \multicolumn{2}{|l|}{ Less than 1000 birr $(<\$ 50)^{*}$} \\
\hline $1001-2000$ birr $(\$ 50-\$ 100)$ & 0.62 (0.49 to 0.77$)$ \\
\hline 2001-3000 birr $(\$ 100-\$ 150)$ & 0.42 (0.32 to 0.57$)$ \\
\hline 3001-4000 birr ( $\$ 150-\$ 200)$ & 0.45 (0.29 to 0.69$)$ \\
\hline 4001-5000 birr $(\$ 200-\$ 250)$ & 0.84 (0.53 to 1.33 ) \\
\hline Above 5000 birr $(>\$ 250)$ & $0.62(0.34$ to 1.15$)$ \\
\hline \multicolumn{2}{|l|}{ Current marital status } \\
\hline \multicolumn{2}{|l|}{ Never married ${ }^{*}$} \\
\hline Married/cohabited & 0.57 (0.17 to 1.97$)$ \\
\hline Separated/divorced & 1.01 (0.83 to 1.22$)$ \\
\hline Widowed & 1.61 (0.98 to 2.63 ) \\
\hline \multicolumn{2}{|l|}{ Educational level } \\
\hline \multicolumn{2}{|l|}{ No Education* } \\
\hline Primary first cycle (1-4) & 1.06 (0.79 to 1.43$)$ \\
\hline Primary second cycle (5-8) & 0.83 (0.65 to 1.07$)$ \\
\hline Secondary and above & 0.92 (0.68 to 1.25$)$ \\
\hline \multicolumn{2}{|c|}{ Frequency of alcohol consumption } \\
\hline \multicolumn{2}{|l|}{ Never $^{\star}$} \\
\hline $2-4$ days a month & 1.15 (0.69 to 1.89$)$ \\
\hline $2-3$ days a week & 1.24 (0.78 to 1.96$)$ \\
\hline 4 or more days a week & 2.33 (1.47 to 3.73 ) \\
\hline \multicolumn{2}{|c|}{$\begin{array}{l}\text { Drunk so much and cannot remember what } \\
\text { happened the next day }\end{array}$} \\
\hline \multicolumn{2}{|l|}{$\mathrm{No}^{*}$} \\
\hline Yes, in the last 30 days & 1.34 (1.05 to 1.72$)$ \\
\hline Yes, before last 30 days & 1.07 (0.75 to 1.52$)$ \\
\hline \multicolumn{2}{|c|}{ Frequency of heavy episodic drinking } \\
\hline \multicolumn{2}{|l|}{ Never ${ }^{*}$} \\
\hline Less than monthly & 1.61 (1.12 to 2.32$)$ \\
\hline Monthly & 1.71 (1.24 to 2.38$)$ \\
\hline Weekly & 1.04 (0.78 to 1.38$)$ \\
\hline Daily or almost daily & 1.49 (1.06 to 2.11$)$ \\
\hline \multicolumn{2}{|c|}{ Frequency of khat chewing in a week } \\
\hline \multicolumn{2}{|c|}{ Never* } \\
\hline Less than once a week & 0.83 (0.59 to 1.16$)$ \\
\hline 1-2 days per week & 2.13 (1.61 to 2.83 ) \\
\hline $3-4$ days per week & 2.15 (1.55 to 2.98 ) \\
\hline 5-7 days per week & 1.06 (0.83 to 1.36$)$ \\
\hline \multicolumn{2}{|l|}{ Condom breakage } \\
\hline \multicolumn{2}{|l|}{$\mathrm{No}^{*}$} \\
\hline Yes & 1.26 (1.03 to 1.55$)$ \\
\hline
\end{tabular}

${ }^{*}$ Reference category.

localities, involving the police force in violence prevention activities is crucial and should be one of the first step. In addition, a peer education programme led by the sex workers could be an additional strategy. Such a programme could help FSWs to create an information sharing platform to discuss the incidences of violence, types of perpetrators and so on, which could raise awareness and help them to become more alert.

Furthermore, an association between alcohol use and higher frequency of physical violence and rape was reported. In particular, FSWs who consume alcohol $>4$ days per week and those with experience of HED were significantly more likely to experience violence. Several studies conducted in Ethiopia, Uganda and Kenya also reported similar findings. 9101219 A large proportion of FSWs use alcohol prior to or during sex to help them to solicit clients and overcome their shyness. ${ }^{35} 36$ In particular, high level of alcohol consumption places FSWs at a disadvantage by intensifying their vulnerability. ${ }^{8}$ Research reviews also report that alcohol use impairs FSWs' ability to detect the risk of violence and increases their vulnerability to risk-prone situations. ${ }^{3738}$ The consequences of HED are not just limited to the physical effects of intoxication but further expose them to violence and risky sexual behaviours.

Correspondingly, chewing khat more days in a week was significantly associated with experience of physical violence and rape. After chewing khat, some of the users consume alcohol-containing beverages to decrease the level of stimulation. Although there is no previous study on the relationship between khat chewing and experience of violence among FSWs, most FSWs chew khat before departing for work. In the bar, they drink alcohol to minimise the effect, which in turn exposes them to HED and violence. Further studies should assess the independent contribution of khat chewing to increasing violence occurrence.

The extent to which alcohol use and khat chewing are risk factors for the occurrence of experiences of violence must be interpreted with caution. Since physical beating was measured within the last 12 months and rape was measured since they started selling sex, the participants' current khat chewing or alcohol consumption status might not be an accurate indicator of their consumption patterns at the time of the violence. In addition, the current use of substances might be a means to cope with the trauma related to the experience of violence.

In addition, the resistance to condom use from clients and the violence experience may create a difficult situation for FSWs with regard to the proper use of condoms, which further exposes FSWs to HIV and other STIs. In this study, there was a significant relationship between condom breakage and history of physical beating and rape. Even though there was no significant association between HIV and violence, the proportion of HIV positive FSWs in the sample was high $(23 \%)$. A study conducted in Benin reported a similar finding concerning the association between condom breakage and violence, but unlike our study there was a significant association between HIV and violence experience. ${ }^{23}$ This finding indicates that solely providing condoms will not be effective to prevent HIV and other STIs transmission. Instead, working on 
factors that contribute to improper use of condoms (such as violence) could be an additional strategy for HIV prevention programme.

In general, our study demonstrates that sex workers are particularly vulnerable to physical beating and rape. Nevertheless, the harm reduction programme among FSWs in Ethiopia is poor. Given the associations between violence and unprotected sex, the HIV control programme may not accomplish its goal of reducing the number of new infections without also addressing violence. Therefore, combining both programme could yield better results with regard to attaining epidemic control as well as reducing the harm associated with violence. In addition, this study shows that different factors (such as sex-selling venues, the age of FSWs, level of alcohol use and so on) were associated with violence among FSWs, signifying the need for different approaches to minimise the incidence of violence. ${ }^{39}$ At the individual level, efforts to reduce violence could focus on developing educational materials and creating awareness for sex workers about their legal rights and about how to prevent, reduce and respond to violence. ${ }^{40}$ In addition, involving the community in the prevention programme could play a vital role especially towards reducing stigma and discrimination towards FSWs, which in turn would create a suitable environment for FSWs to stand up for their rights. Furthermore, involving police and law enforcement authorities to reduce harassment could play a greater role in violence reduction.

Finally, there were some similarities but also differences concerning the predictors of rape and physical violence. For example, being in the younger age group was a significant predictor of physical beating but not rape, and having lower income was associated with rape but not with physical beating. Nevertheless, based on the current data, it is difficult to draw any conclusions about why one variable would matter for physical beating but not for rape. The reasons underlying the differences are currently unknown, and further research might be required to gain an understanding of the patterns observed.

\section{Methodological considerations}

There are a limited number of studies on violence among FSWs in Ethiopia and the existing studies are restricted to one city. ${ }^{910}$ One of the strengths of this study is that it involves multiple sites (11 large towns) across the country. The second strength is the sampling technique; the study used a RDS, which is a strategy recommended for hard-to-reach populations and which is believed to give a representative sample of the target population. The third strength is the assessment of FSWs' HIV status on site using the national testing algorithm. In addition, the pilot study conducted prior to the actual implementation added strength to the main study protocol.

This study also had limitations. First, sexual and physical violence are sensitive topics that are subject to underreporting because of social desirability bias. Second, recall bias could have occurred because participants were asked about physical violence in the last year and rape since they started selling sex. We tried to minimise underreporting through intense interviewer training. In addition, since it was a cross-sectional study, participants were assessed only once; thus, it would be difficult to infer the temporal association between a risk factor and the outcome measures, that is, physical violence and rape.

Furthermore, the results regarding correlates of physical and sexual violence among FSWs in Ethiopia might have limited generalisability across settings. However, these results are likely to be relevant for other FSWs in other African countries that have a similar setting as Ethiopia, and may inform targeted prevention strategies for this key population.

\section{CONCLUSION}

In general, FSWs are vulnerable to physical and sexual violence, and the risk increases when they are younger, street-based and are high consumers of alcohol or khat. Therefore, to reduce physical and sexual violence, strategies to secure and improve their work environment should be a critical component of targeted interventions. Increasing awareness regarding the role of khat chewing and alcohol drinking towards vulnerability to violence should be an integral component of HIV prevention and violence reduction programme. In addition, targeted efforts should be made for the younger FSWs in order to reduce their vulnerability.

Acknowledgements We would like to express gratitude to the study participants and the data collectors.

Contributors MDA and AA developed the study design. MDA analysed and interpreted the data and drafted the manuscript. AA was involved in the data analysis and interpretation, and in the writing of the manuscript. TTB was involved in the interpretation of the data and contributed to the writing of the manuscript.

Funding The authors have not declared a specific grant for this research from any funding agency in the public, commercial or not-for-profit sectors.

Competing interests None declared.

Patient consent for publication Not required.

Provenance and peer review Not commissioned; externally peer reviewed.

Data availability statement No additional data available.

Open access This is an open access article distributed in accordance with the Creative Commons Attribution Non Commercial (CC BY-NC 4.0) license, which permits others to distribute, remix, adapt, build upon this work non-commercially, and license their derivative works on different terms, provided the original work is properly cited, appropriate credit is given, any changes made indicated, and the use is non-commercial. See: http://creativecommons.org/licenses/by-nc/4.0/.

\section{REFERENCES}

1. Jewkes R. Intimate partner violence: causes and prevention. The Lancet 2002;359:1423-9.

2. World Health Organization. Global and regional estimates of violence against women: prevalence and health effects of intimate partner violence and non-partner sexual violence: Executive summary. Available: https://apps.who.int/iris/bitstream/handle/10665/85239/ 9789241564625_eng.pdf;jsessionid=6E940F74EB1BC5204EEDE0FC 6D26F358? sequence $=1$

3. Glasier A, Gülmezoglu AM, Schmid GP, et al. Sexual and reproductive health: a matter of life and death. The Lancet 2006;368:1595-607. 
4. Perry A. Risk factors of gender-based sexual violence. RTM Insights.23. Available: http://www.rutgerscps.org/uploads/2/7/3/7/ 27370595/riskfactorsofgenderbasedsexual_violence_rtminsights23. pdf

5. Godwin J. Sex work and the law in Asia and the Pacific. Bangkok: United Nations Development Programme.

6. World Intellectual Property Organization. The Criminal Code of the Federal Democratic Republic of Ethiopia Article 634:(Proclamation No. 414/2004), 2004.

7. World Health Organization. Addressing violence against women and achieving the millennium development goals, 2005.

8. World Health Organization,. Addressing violence against sex workers, 2013. Available: https://www.who.int/hiv/pub/sti/sex worker_implementation/swit_chpt2.pdf

9. Alemayehu M, Yohannes G, Damte A, et al. Prevalence and predictors of sexual violence among commercial sex workers in northern Ethiopia. Reprod Health 2015;12:47.

10. Mooney A, Kidanu A, Bradley HM, et al. Work-Related violence and inconsistent condom use with non-paying partners among female sex workers in Adama City, Ethiopia. BMC Public Health 2013;13:771.

11. Misganaw AC, Worku YA. Assessment of sexual violence among street females in Bahir-Dar town, North West Ethiopia: a mixed method study. BMC Public Health 2013;13:825.

12. Schwitters $A$, Swaminathan $M$, Serwadda $D$, et al. Prevalence of rape and Client-Initiated gender-based violence among female sex workers: Kampala, Uganda, 2012. AIDS Behav 2015;19:68-76.

13. Beattie TSH, Bhattacharjee P, Ramesh BM, et al. Violence against female sex workers in Karnataka state, South India: impact on health, and reductions in violence following an intervention program. BMC Public Health 2010;10.

14. Kelvin EA, Sun X, Mantell JE, et al. Vulnerability to sexual violence and participation in sex work among high-end entertainment centre workers in Hunan Province, China. Sex Health 2013;10:391-9.

15. Wolffers I. Violence repression and other health threats. Research for sex work 2001;4:1-2 https://www.nswp.org/sites/nswp.org/files/ research-for-sex-work-4-english.pdf

16. Hanck SE, Blankenship KM, Irwin KS, et al. Assessment of selfreported sexual behavior and condom use among female sex workers in India using a polling box approach: a preliminary report. Sex Transm Dis 2008;35:489-94.

17. Parcesepe AM, L'Engle KL, Martin SL, et al. The impact of an alcohol harm reduction intervention on interpersonal violence and engagement in sex work among female sex workers in Mombasa, Kenya: results from a randomized controlled trial. Drug Alcohol Depend 2016;161:21-8.

18. Wechsberg WM, Luseno WK, Lam WKK, et al. Substance use, sexual risk, and violence: HIV prevention intervention with sex workers in Pretoria. AIDS Behav 2006;10:131-7.

19. Chersich MF, Luchters SMF, Malonza IM, et al. Heavy episodic drinking among Kenyan female sex workers is associated with unsafe sex, sexual violence and sexually transmitted infections. Int $J$ STD AIDS 2007;18:764-9.

20. Church S, Henderson M, Barnard M. Violence by clients towards female prostitutes in different work settings: questionnaire survey. BMJ 2001;322:524-5.

21. El-Bassel N, Witte SS, Wada T, et al. Correlates of partner violence among female street-based sex workers: substance abuse, history of childhood abuse, and HIV risks. AIDS Patient Care STDS 2001;15:41-51.
22. Masvawure TB, Mantell JE, Tocco JU, et al. Intentional and unintentional condom breakage and slippage in the sexual interactions of female and male sex workers and clients in Mombasa, Kenya. AIDS Behav 2018;22:637-48.

23. Tounkara FK, Diabaté S, Guédou FA, et al. Violence, condom breakage, and HIV infection among female sex workers in Benin, West Africa. Sex Transm Dis 2014;41:312-8.

24. Choi SYP, Chen KL, Jiang ZQ. Client-perpetuated violence and condom failure among female sex workers in southwestern China. Sex Transm Dis 2008;35:141-6.

25. Wilson KS, Deya R, Yuhas K, et al. A prospective cohort study of intimate partner violence and unprotected sex in HIVpositive female sex workers in Mombasa, Kenya. AIDS Behav 2016;20:2054-64.

26. Okal J, Chersich MF, Tsui S, et al. Sexual and physical violence against female sex workers in Kenya: a qualitative enquiry. AIDS Care 2011;23:612-8.

27. Ethiopian public health institute. Ethiopian national key population HIV Bio-behavioral surveillance round I report 2013.

28. Ethiopian public health institute in collaboration with UNAIDS. Hiv related estimates and projections for Ethiopia-2015.

29. Decker MR, Lyons C, Billong SC, et al. Gender-Based violence against female sex workers in Cameroon: prevalence and associations with sexual HIV risk and access to health services and justice. Sex Transm Infect 2016;92:599-604.

30. Lyons CE, Grosso A, Drame FM, et al. Physical and sexual violence affecting female sex workers in Abidjan, Côte d'Ivoire: prevalence, and the relationship with the work environment, HIV, and access to health services. J Acquir Immune Defic Syndr 2017;75:9-17.

31. World Health Organization. Assessment of khat (Catha edulis Forsk) 34th ECDD 2006/4.4. Available: http://www.who.int/medicines/areas/ quality_safety/4.4KhatCritReview.pdf

32. Wilson KS, Deya R, Masese L, et al. Prevalence and correlates of intimate partner violence in HIV-positive women engaged in transactional sex in Mombasa, Kenya. Int J STD AIDS 2016;27:1194-203.

33. Semple SJ, Stockman JK, Pitpitan EV, et al. Prevalence and correlates of client-perpetrated violence against female sex workers in 13 Mexican cities. PLoS One;10:e0143317.

34. Silverman JG. Adolescent female sex workers: invisibility, violence and HIV. Arch Dis Child 2011;96:478-81.

35. Kumar Sharma S, Kant Singh S, Sharma S, Singh S, Talukdar B. Understanding the factors associated with alcohol use among female sex workers in a high HIV prevalence northeast state of India. J Infec Dis Treat 2016;2.

36. Wechsberg WM, Luseno WK, Lam WK. Violence against substanceabusing South African sex workers: intersection with culture and HIV risk. AIDS Care 2005; 17:55-64

37. George WH, Stoner SA. Understanding acute alcohol effects on sexual behavior. Annu Rev Sex Res 2000;11:92-124.

38. Mbonye M, Rutakumwa R, Weiss $\mathrm{H}$, et al. Alcohol consumption and high risk sexual behaviour among female sex workers in Uganda. Afr $J$ AIDS Res 2014;13:145-51.

39. Reed E, Gupta J, Biradavolu M, et al. The context of economic insecurity and its relation to violence and risk factors for HIV among female sex workers in Andhra Pradesh, India. Public Health Rep 2010;125(Suppl 4):81-9.

40. Hail-Jares K, Chang RCF, Choi S, et al. Intimate-partner and clientinitiated violence among female street-based sex workers in China: does a support network help? PLoS One 2015;10:e0139161. 